\title{
UNDER THE MICROSCOPE
}

\section{PJOHYS}

Jennifer T. Go, MD'

Jose M. Carnate Jr., MD ${ }^{1,2}$

'Department of Laboratory Medicine

The Medical City

Ortigas Avenue, Pasig City

${ }^{2}$ Department of Pathology

College of Medicine

University of the Philippines Manila
Correspondence: Dr. Jose M Carnate, Jr. Department of Pathology

College of Medicine, University of the Philippines Manila

547 Pedro Gil St.، Ermita, Manila 1000

Philippines

Phone (632) 526-4450

Telefax (632) 400-3638

Email:jmcjpath@gmail.com

The authors declared that this represents original material that is not being considered for publication or has not been published or accepted for publication elsewhere, in full or in part, in print or electronic media; that the manuscript has been read and approved by the authors, that the requirements for authorship have been met by the authors, and that the authors believe that the manuscript represents honest work.

Disclosures: The authors signed a disclosure that there are no financial or other (including personal) relationships, intellectual passion, political or religious beliefs, and institutional affiliations that might lead to a conflict of interest.

\section{(c) $9 \Theta \Theta$}

Creative Commons (CC BY-NC-ND 4.0)

Attribution - NonCommercial - NoDerivatives 4.0 International

\section{Ameloblastic Fibrosarcoma of the Mandible}

A 32-year-old Filipino woman presented with a 3-year history of slowly enlarging left hemimandibular mass with no associated symptoms. Previous biopsy showed ameloblastoma. Imaging revealed a translucent multiloculated mass with ill-defined borders. (Figure 1) On examination, the mass was irregularly shaped, measures $40 \times 39 \mathrm{~cm}$, slightly hyperpigmented and erythematous, warm with visible vessels. The patient underwent left segmental mandibulectomy with reconstruction and the specimen was sent for histopathologic evaluation.

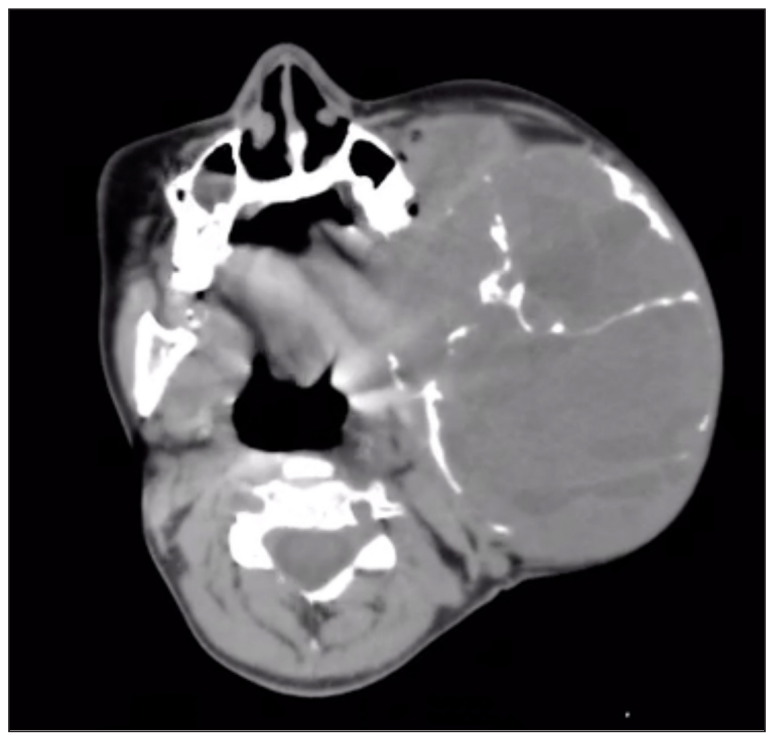

Figure 1. Axial CT Scan showing a large multiloculated, radiolucent mass with irregular borders on the left mandible.
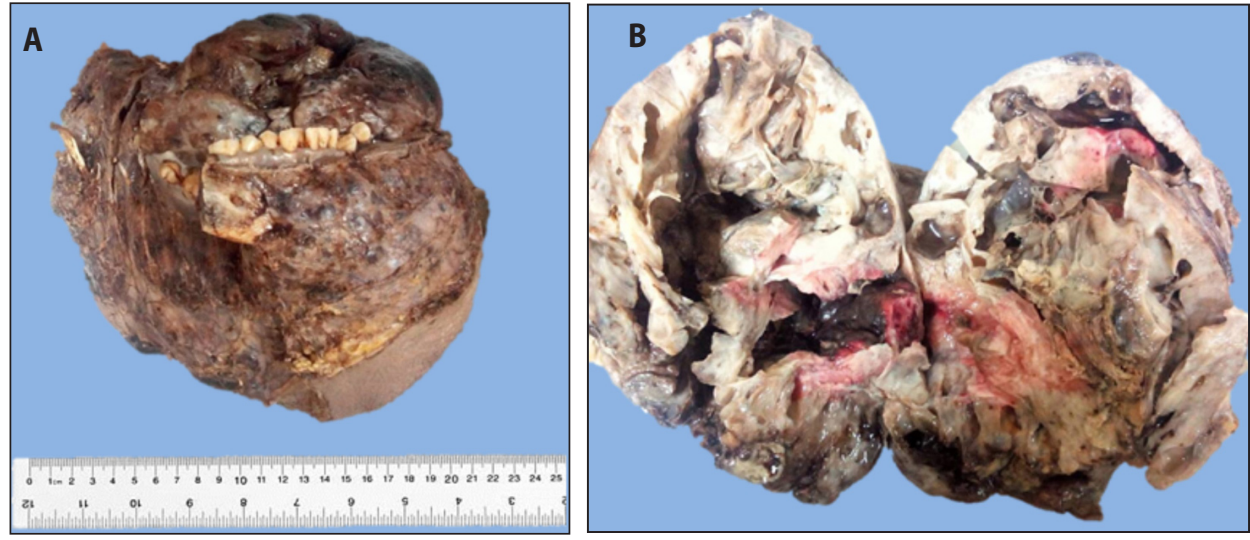

Figure 2. A. Mandibulectomy specimen - the body, angle, ramus and condyles of the left mandible are no longer identifiable grossly. B. Cut section showing cystic spaces filled with necrotic debris and purulent material. 


\section{UNDER THE MICROSCOPE}

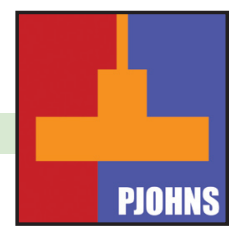

Received was a mandibulectomy specimen weighing 1850 grams and measuring $17 \times 14.5 \times 14 \mathrm{~cm}$. The body, angle, ramus and condyles of the left hemimandible are no longer identifiable grossly. There are ten teeth attached. Cut sections show multiple cystic spaces which measure from 0.8 to $15.0 \mathrm{~cm}$ in widest diameter, filled with abundant red-brown necrotic debris and yellow-brown purulent material. The mass has a grey-tan soft to fibrous cut surface with focal gritty areas. (Figure 2)

Microscopic examination shows a biphasic neoplasm composed of benign epithelial and malignant mesenchymal components. (Figure 3) The benign epithelial component is arranged in islands and strands with peripheral palisading, composed of bland cells without atypia. (Figure 4) The abundant mesenchymal component is composed of spindle cells in fascicles. The cells are moderately pleomorphic with enlarged hyperchromatic nuclei, prominent nucleoli, coarse chromatin and scant cytoplasm. The cells are suspended within loose stroma with variable degree of cellularity. Some mitoses are noted. (Figure 5)

Ameloblastic fibrosarcoma (AFS) belongs to a group of odontogenic

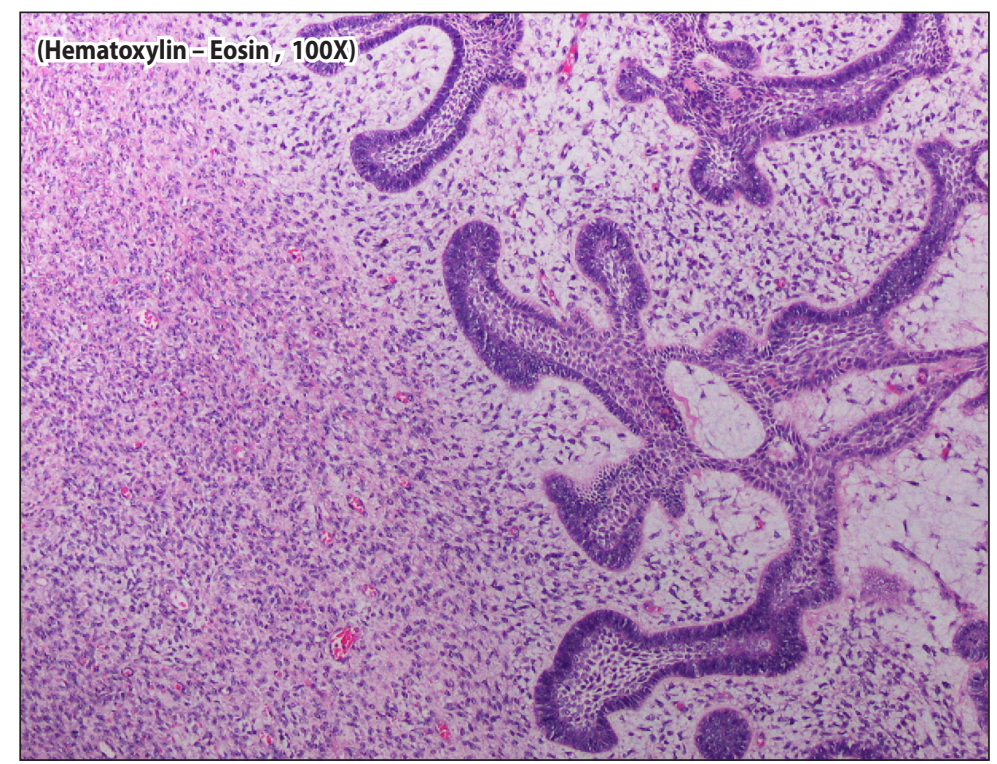

Figure 3. Ameloblastic Fibrosarcoma (AFS) biphasic morphology composed of benign epithelial and malignant mesenchymal components. (Hematoxylin-Eosin, 100X magnification).

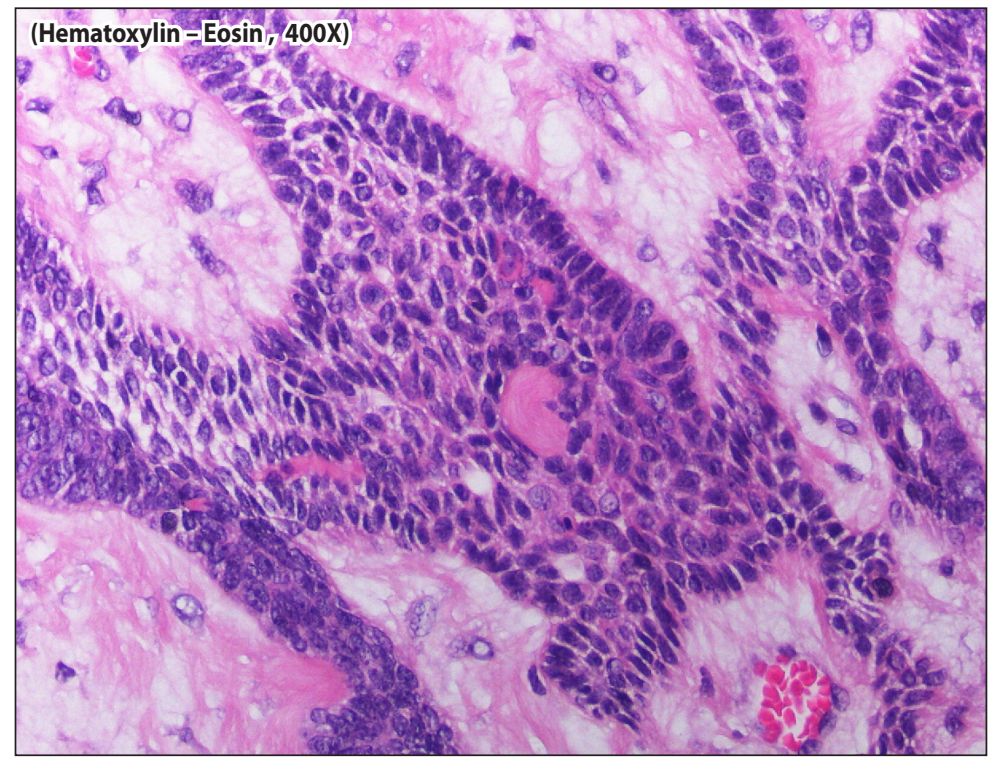

Figure 4. The benign epithelial component is arranged in islands and strands with peripheral palisading, composed of bland cells without atypia. (Hematoxylin-Eosin, 400X magnification). 


\section{UNDER THE MICROSCOPE}

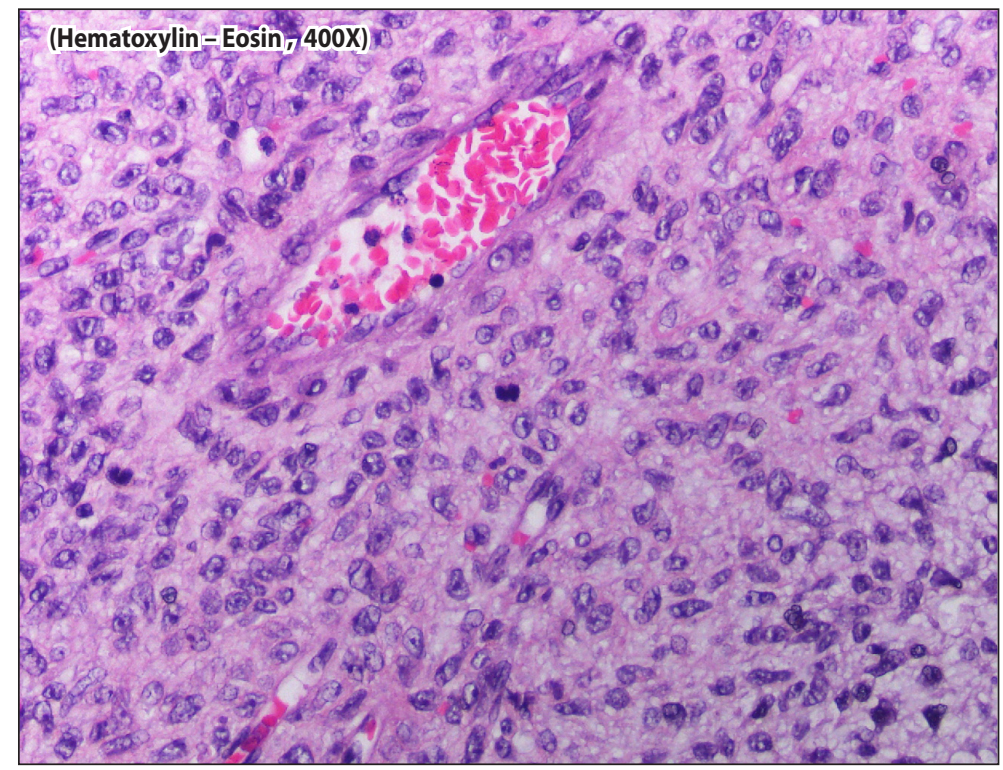

Figure 5. Abundant mesenchymal component showing marked cellularity, nuclear pleomorphism with hyperchromasia, prominent nucleoli, coarse chromatin and scant cytoplasm. Brisk mitotic activity is seen. (Hematoxylin-Eosin, 400X magnification).

sarcomas in which the epithelial component is cytologically benign while the ectomesenchymal component shows malignant features. The AFS is the most common type among the odontogenic sarcomas. It is regarded as the malignant counterpart of ameloblastic fibroma (AF). Although most cases arise de novo, the documentation of a prior or pre-existing precursor lesion from ameloblastic fibroma suggests otherwise. ${ }^{1,2}$ A study by Kobayashi et al. suggested that up to one-third of AFS arise from AF while a review of literature by Lai et al. demonstrated that $51 \%$ of AFS had previously documented AF at the same site, providing supporting evidence of a malignant transformation. ${ }^{3}$

Ameloblastic fibrosarcoma has a reported age range of 3 - 89 years, with overall mean patient age of 27.3 years. In cases of prior diagnosis of AF, AFS can occur at a mean patient age of 33 years whereas a mean patient age of 23 years where no prior diagnosis of AF was documented. ${ }^{1,4}$ It mainly affects males in the third or fourth decade of life and the posterior mandible is the most commonly affected site with ratio of mandibular to maxillary incidence of 4:1.1,3,4 The clinical presentation is usually that of a painful, enlarging mass and most lesions are radiographically translucent and multiloculated with illdefined borders. ${ }^{2,4}$

The histologic features of AFS reveal a mixture of benign odontogenic epithelium ranging from budding and branching cords to large islands composed of columnar or cuboidal peripheral cells arranged in palisading pattern, and an abundant malignant mesenchymal component showing marked cellularity, nuclear pleomorphism and moderate mitotic figures. ${ }^{1,2,3}$ Ameloblastic fibroma differs from AFS by having no malignant component and immunohistochemical stains have been suggested to provide distinction, particularly when identifying a low-grade fibrosarcoma. The malignant component of AFS will show positivity in p53 and PCNA and will have a higher Ki-67 expression than AF., ${ }^{3,4}$

Although AFS are low to intermediate-grade sarcomas, a high incidence of recurrence is reported - about one third of patients experience recurrence and overall mortality rate is $25 \%$. However, only less than $5 \%$ of cases with metastases have been reported. ${ }^{1,3}$ Long term follow up is thus indicated.

\section{REFERENCES}

1. Wright JM. Odontogenic Sarcomas. In: El-Naggar AK, Chan JKC, Grandis JR, Takata T, Slootweg PJ (editors). WHO Classification of Head and Neck Tumours, WHO Classification of Tumours, 4th Edition, Volume 9. Lyon: International Agency for Research on Cancer IARC; 2017, p. 214.

2. Servato JPS, De Faria PR, Ribeiro CV, Cardoso SV, Dias FL, Eisenberg ALA, Loyola AM. Ameloblastic fibrosarcoma: a case report and literature review. Braz Dent J. 2017 Mar-Apr; 28(2):262-272. DOI: 10.1590/0103-6440201701050 PMID: 28492759

3. Loya-Solis A. Gonzalez-Colunga KJ, Perez-Rodriguez CM, Ramirez-Ochoa NS, CecenasFalcon L, Barboza-Quintana O. Ameloblastic fibrosarcoma of the mandible: a case report and brief review of the literature. Case Rep Pathol. 2015;2015:245026. Epub 2015 Mar 10 DOI: 10.1155/2015/245026 PMID: 25861504 PMCID: PMC4377457.

4. Al Shetawi AH, Alpert EH, Buchbinder D, Urken ML. Ameloblastic fibrosarcoma of the mandible: a case report and a review of the literature. J Oral Maxillofac Surg. 2015 Aug;73(8):1661.e1-7. Epub 2015 Apr 10. DOI: 10.1016/j.joms.2015.03.066 PMID: 25921823. 